\title{
Building the Alliance of Indigenous Math Circles
}

\section{Bob Klein and Tatiana Shubin}

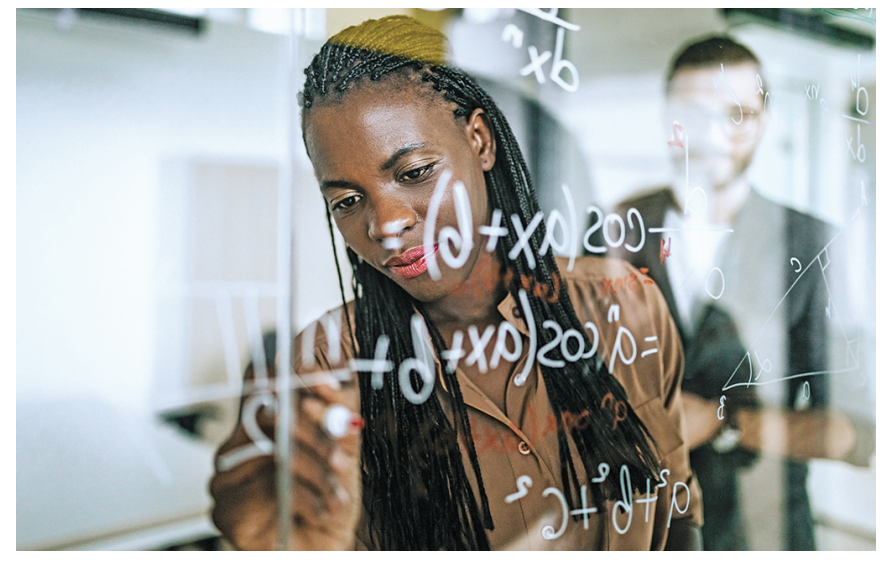

To say that US Native Americans are underrepresented in mathematics is itself an understatement.

In 2010 the census recorded 5.2 million people in the United States who identified as American Indian or Alaskan Native, either alone or in combination with one or more other races. Of those, a mere twelve hold a mathematics PhD. ${ }^{1}$

Compare this with Hungary, which has almost twice the population-9.8 million. From 1993 to the present, 460 mathematics PhDs were awarded there. ${ }^{2}$ (We looked

Bob Klein is interim dean of Ohio University Eastern and associate professor of mathematics at Ohio University. He is the executive director of the Alliance of Indigenous Math Circles (AIMC). His email address is kleinr@ohio.edu.

Tatiana Shubin is professor of mathematics at San Jose State University. She is co-director of the AIMC. Her email address is tatiana. shubin asjsu.edu.

${ }^{1}$ Dr. Robert Megginson, cf. https://sciences.ucf. edu/news /math-and-native-american-culture/ for details.

${ }^{2}$ Országos Doktori Tanács (Hungarian Doctoral Council), https:// doktori . hu/index . php?menuid=110\&lang=EN.

For permission to reprint this article, please contact: reprint -permission@ams.org.

DOI: https://dx.doi.org/10.1090/noti 1852 for the total number of living people with PhDs, but these data were not available.)

Kazakhstan has just over three times the population, 17.8 million, with people in rural and remote areas. Four hundred Kazakhstanis hold PhDs in mathematics. ${ }^{3}$ Were we to regard the US Native American/Alaskan Native population as a nation, Hungary and Kazakhstan suggest that we would expect to see between 160 and 244 mathematics PhD holders in that nation. We clearly have a long road to go to match Hungary or Kazakhstan.

But why does this comparison matter? When a distinct group of people, in this case marked by their identification as American Indians or Alaskan Natives, do not participate in mathematics, the question that arises naturally is, "Why?" Biological explanations are both racist and scientifically unsupported, though science took some centuries to

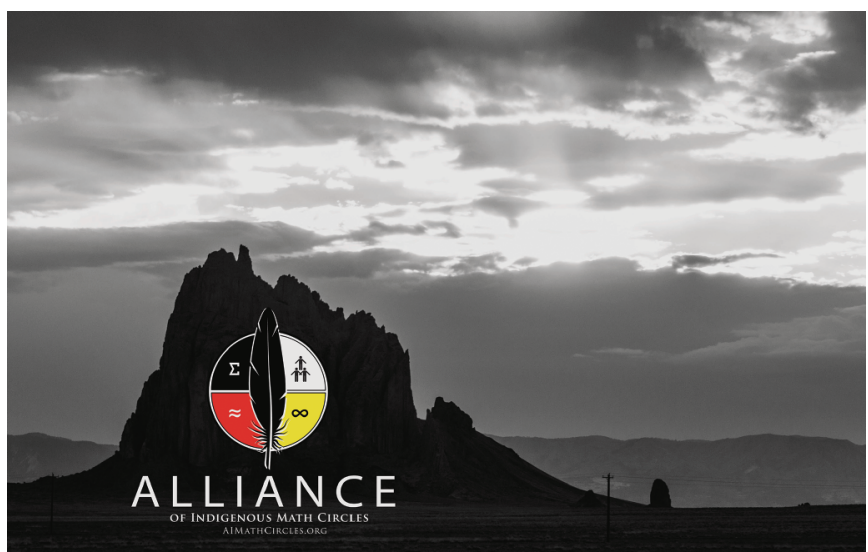

Shiprock looms large over the New Mexico desert, not far from the site of the AIMC at Navajo Prep Summer Math Camp.

${ }^{3}$ Personal correspondence with Dr. Askar Dzhumadildayev, a Kazakh mathematician, doctor of physics and mathematics, professor, and Full Member of the Kazakhstan National Academy of Science. He was also member Supreme Council of Kazakh SSR and Republic of Kazakhstan. 
get there. ${ }^{4}$ Cultural explanations would require assuming some key commonality to all American Indian or Alaskan Native peoples that contraindicated participation in mathematics. Alternatively, one could ask whether or not there exists a "culture of mathematics" that embodies certain norms that constitute a barrier for a group of people. Such questions are beyond the scope of this paper, though the related issue of how people construct their identity relative to tradition, affiliation, and intellectual pursuits and practices is not only relevant, but it informs our model for engaging indigenous communities and mathematicians in mathematical problem solving.

A further important question concerns the issue of whether or not mathematics itself should be an essential part of everyone's education and which outcomes in particular matter most to the education of all. Readers of the Notices probably need little convincing of the importance of mathematics but ought to consider the outcomes and methods of a "school mathematics" (thought of here as typical K-12 curriculum in the United States) versus what they value most when thinking of mathematics. What we, the authors, see as "beautiful mathematics" seems largely to be absent from the encyclopedic techniques and formulas that constitute mathematics curricula in K-16 settings. To us, the "school mathematics," necessary to some extent, is not only an insufficient exposure to mathematics, but by itself paints for the general populace a picture of mathematics incongruent with the beauty and joy that we find in it. As students shape their identities relative to abilities and affinities toward subjects, we want them to value mathematics as beautiful, intriguing, and powerful, and to see themselves as capable and creative practitioners of mathematics.

The Alliance of Indigenous Math Circles (AIMC) helps indigenous communities to provide experiences and infrastructure for students and teachers to realize the beauty and power of mathematics, recognizing that this involves the concomitant valuing of their budding mathematical and indigenous identities (not to mention other identities). By combining work with professional mathematicians and tribal elders, we covalue mathematics and culture so that an indigenous student sees no disjunction between being "indigenous" and a "mathematician" - we are working within culture and identity to try to stimulate a robust next generation of "indigenous mathematicians."

Targeting mathematics has broad implications given the extent to which the " $\mathrm{M}$ " supports the "STE" of STEM. While it is true that mathematics is the basis for all STEM fields, it is arguably the most significant prerequisite for success in the world of post-secondary opportunities. And mathematics is far more than the checklist set of skills found in school

\footnotetext{
${ }^{4}$ See, for instance, Gould, Steven J. The Mismeasure of Man. New York: W.W. Norton \& Co., 1991.
}

mathematics. It represents the purest subject for expanding the human mind's capacity for critical thinking and problem solving. As such, mathematics prepares people with tools, mindsets, and techniques to fashion a successful and fulfilling life regardless of professional occupation. ${ }^{5}$

The Alliance of Indigenous Math Circles (AIMC https://aimathcircles.org) is devoted to bringing mathematicians and math professionals into direct contact with indigenous students and teachers throughout the United States and abroad in order to improve and strengthen their grasp of and attitude toward mathematics. And AIMC promotes the culture of problem solving within the framework of the indigenous culture, to both promote that culture in its own right and to bring more indigenous people into STEM fields. ${ }^{6}$

The AIMC is an initiative that grew out of the Navajo Nation Math Circles project (NNMC, launched in 2012). NNMC historically has included a number of components including mathematicians visiting schools and running math circle sessions for students, professional development workshops for teachers, and a summer math camp at Diné College in Tsaile, AZ. This work has demonstrated that math circles and summer math camps combining mathematics and indigenous culture led students who were not otherwise considering it to attend a college or university, many pursuing STEM-related degrees. Moreover, five years of the project gave ample opportunity to refine the model, confirming some elements as productive (e.g., mathematician visits to schools, summer camps) and others as more problematic (e.g., school-year pen-pal programs between mathematicians and K-12 students). In 2017, a group of directors from the NNMC project recognized that the model could be shared more broadly, requiring a new direction and adopting a new name that was more inclusive and representative of the mission. Thus, the Alliance of Indigenous Math Circles was born with the purpose of sharing the model with other indigenous communities and to provide a network of support for sustaining the work within and by those communities.

\footnotetext{
${ }^{5}$ Two excellent examples of this more general power of mathematics can be found in Avoid Hard Work! ... and Other Encouraging Problem-Solving Tips for the Young, the Very Young, and the Young at Heart, (Droujkova M, Tanton J, McManaman Y, Natural Math, 2016) and The 5 Elements of Effective Thinking (Burger E, Starbird M, Princeton University Press, 2012).

${ }^{6}$ While our immediate focus is on indigenous peoples living within the national boundaries of the United States, AIMC staff have also worked with indigenous peoples abroad. Available demographics use the terms "American Indian/Alaskan Native" (as in the case of the US Census) and sometimes "Native Americans" to refer to indigenous people living within US boundaries. We recognize that the term "American" is itself contested and is seen by many as broadly applicable to people living throughout North, Central, and South America. For this reason, and after conversation with our indigenous colleagues in the project, we favor the term "indigenous" and further specify "in the US" where applicable.
} 
To date, the AIMC has had student and teacher participants representing Diné (Navajo), Hopi, and Apache tribes, as well as members of the nineteen Pueblo Tribes of New Mexico. We have had the guidance, support, and participation of elders from the Diné, Hopi, Chickasaw, Choctaw, and Pomo tribes/nations as well as the elders of the American Indian Science and Engineering Society (AISES). The AIMC is therefore a "circle" in its own right, a gathering of those who work to make the discipline and practice of mathematics as diverse and inclusive as possible. ${ }^{7}$

The contributions of mathematicians have been generous, and their impact significant. For instance, in March and April 2018, AIMC sponsored three mathematiciansAdnan Sabuwala and Maria Nogin of California State University, Fresno, and Tatiana Shubin of San Jose State University_to run a series of math circle sessions on Diné and Hopi reservations, at two Indian boarding schools (Navajo Preparatory School in Farmington, NM, and Santa Fe Indian School) as well as some rural schools in northern New Mexico. We visited sixteen schools, running two to four sessions in each. Altogether more than 500 students and forty-four teachers attended these sessions and enjoyed the beauty and challenge of doing math circle-style mathematics.

Besides school visits, Tatiana Shubin and Donna Fernandez, a Navajo Prep School math teacher serving as an AIMC Regional Coordinator, ran a workshop for teachers at Tuba City High School (AZ). We also helped to run Julia Robinson Math Festivals at Tuba City Boarding School and Many Farms Community Schools (AZ); hundreds of students from grades $1-8$ visited these festivals and had fun sharing the joy of problem solving with one another. Other regional coordinators such as Craig Young (Diné reservation) and LaVerne Lomakema (Hopi reservation) are working within their communities to plan events.

For two years in a row, in 2017 and 2018, the AIMC Math Camp at Navajo Prep School has been attracting talented kids from the Four Corners states to participate in a residential camp for students nominated by their grades 7-12 teachers. The camp combines extensive and challenging math sessions and Native American cultural activities as well as various STEM and physical activities. This year, students enjoyed a field trip to the mine of a local Navajoowned and operated company, the Navajo Transitional Energy Company (NTEC). In both years, the number of applications exceeded our capacity, and we have had to be selective and purposeful in building our summer cohorts.

Most of the thirty-five students at the camp were Diné (Navajo), but we also had students from Hopi and Apache

\footnotetext{
${ }^{7}$ A colleague recently shared the important distinction between diversity and inclusion: Diversity is being invited to the party, whereas inclusion is being asked to dance. Those who love and promote mathematics ought to be mindful of this distinction, to be sure that we are working beyond simple models of "outreach" toward true "engagement."
}

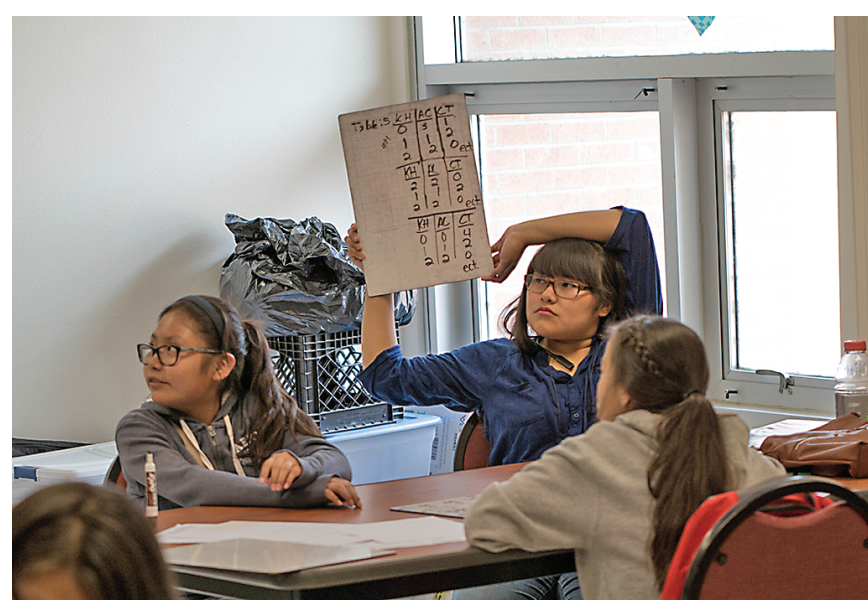

AIMC Summer Math Campers display their results on a probability problem.

tribes. Among the facilitators of math sessions was Frederick Peck (University of Montana, Missoula). Fred has been a team member of the Montana Math Teachers' Circle Network, a group that members of AIMC supported during their startup. Peck and colleagues are working with Montana tribal educators and community members to start math circles programs. This process involves patience and a respectful approach. We operate on a strict principle of only working where we are invited and recognizing that true and productive partnerships, while the longer-term goal, come only after the sequence of

\section{Invitation $\rightarrow$ Cooperation $\rightarrow$ Collaboration $\rightarrow$ Partnership.}

Given the historical traumas endured by generations of tribal members, it takes patience to build the trust and understanding that leads to the initial Invitation stage. As such, expanding the AIMC model requires patience, purpose, and a commitment to ongoing presence. Too often in these communities, initiatives have come and gone, generating the perception of "one-and-done" interventionsfeel-good opportunities that ultimately make the work of developing trust and lasting relationships more difficult. Meaningful partnerships take time, commitment, and acknowledgment that partners come to the table as equals.

Recently, and in reflecting on this principle of Invitation outlined above, we recognized the potential of making the first invitation instead of waiting for an invitation. Rather than waiting to be invited into a community only to hope to share examples of math circles, we instead identify a Champion within a community showing potential interest in AIMC partnership. We invite that Champion to an AIMC event like the successful AIMC Summer Math Camp, and invite them to contribute as they like, to reflect, and to engage after hours in ongoing conversations about the approach and the "goodness of fit" of the AIMC model to the Champion's community. It is an opportunity not unlike a working retreat to engage in conversations with the Cham- 
pion and to determine if there is a workable path forward to an initial Invitation, hopefully leading to Partnership. In Summer 2018, one such Champion from Alaska was Ann Cherrier, a math teacher interested in building math circles within her community and with a focus on schools and teachers who primarily serve Alaskan Native students.

Yet another part of our vision for changing the culture of mathematics recognizes that there is important work to be done in the mentoring relationship between student participants (usually quite young) and math circle facilitators (often older in years though equally young at heart). Moreover, we recognized that the change we wanted to support within the mathematics community required engaging undergraduate students of mathematics directly. To address this gap, we have taken to including talented undergraduate students from universities across the United States to serve as Junior Mentors. Their job is to interact with the student participants and to share with them their love and enthusiasm for mathematics. Sierra Knavel, an undergraduate mathematics major from Ohio University and 2017 Junior Mentor, commented that "Being a peer mentor at the AIMC Math Camp shaped the way I see how accessibility of mathematics outside of school affects the amount of people who study it later on. Specifically, it reminded me of the critical moments in my youth where math was fun, exciting, and puzzling enough to retain my interest as I grew older. Even though undergraduate math is frustrating at times, the AIMC Math Camp reminded me of the positive reasons why I choose to continue with mathematics!"

At the 2018 AIMC Math Camp this role was played by Henry Austin, whose father David Austin is one of the handful of Native Americans holding PhDs in mathematics. Henry's description of his role in the camp is featured below in the "Perspectives." David himself served as our Guest of Honor and delivered a final talk at the camp; his perspective. is similarly included below.

With the help and support of the entire mathematical community, AIMC will continue the work we have started. The AIMC represents a collection of interested and engaged professionals and is not a formal nonprofit. We have been grateful for the financial support of the Carnegie Corporation of New York, and the administrative support of the Mathematical Sciences Research Institute, and we are excited to announce that, beginning in 2019, we will have the administrative support of the American Institute of Mathematics.

\section{Future activity for the AIMC includes the following:}

- Sustaining our flagship AIMC Math Camp at Navajo Preparatory School, inviting teams of Champions from up to three new sites to observe the camp each year. We anticipate having each team include a mathematics professional to serve as a facilitator, $^{8}$ one student camper, and one adult (a teacher, a parent, or a good organizer/administrator from the community). This is an ideal composition for a team of Champions, but even one highly motivated Champion from a site would be welcome.

- Sending mathematicians as visitors to various sites already in operation (e.g., Diné and Hopi schools) as well as prospective sites (e.g., Alaska or Oklahoma). Visitors run math circle sessions for kids and teachers, PD workshops for teachers, and math festivals for students or entire communities. AIMC helps to coordinate and support the visits and collects visitor information.

- Getting the word out and finding Champions. This requires active participation in a number of meetings, including annual meetings of both AISES and SACNAS, running sessions, and distributing informational materials. (We have a great success rate with AISES meetings-when Bob attended in 2016, he met and recruited Donna; in 2017 Tatiana recruited the Montana team.)

- Providing limited financial support, as available, for up to three years to each new site. After the initial three years we will continue our support through Regional Coordinators-experienced math circle leaders who en-

\footnotetext{
${ }^{8} \mathrm{~A} \mathrm{PhD} \mathrm{mathematician} \mathrm{is} \mathrm{not} \mathrm{always} \mathrm{available} \mathrm{in} \mathrm{some} \mathrm{of} \mathrm{the} \mathrm{remote}$ communities in which we work, though scientists, engineers, and others having significant background and training in mathematics content can often serve this purpose.
} 
gage within the AIMC directly to help promote, extend, and support our efforts across regions. Beyond paying Regional Coordinators, AIMC cannot at this point provide monetary support after the initial three years. Each local Indigenous Math Circles (IMC) program would have to seek its own funding, and AIMC will support that effort as we are able, pointing out grant opportunities and helping to shape proposals.

- Maintaining a website with news, materials from the AIMC Math Camp at Navajo Preparatory School, and links to local IMCs. Moreover, starting in 2019, we will have a means for individuals to make financial contributions through the website, supporting our expansion efforts.

- Engaging a Board comprising national leaders with skills and accomplishments in relevant areas such as mathematics, education, indigenous issues, marketing, business, and STEM disciplines. The type of Board and model for meetings/membership was the subject of the meeting, "Founding Board," which met at the 2018 annual AISES meeting in Oklahoma City to help establish a path for the AIMC's future.

Short of seeing the camp, the school classroom visits, the teacher professional development workshops, or the festivals, we know of few better ways of understanding the impact of our approach than to hear directly from those who are engaged in this work. What follows is a series of perspectives, and they offer the reader a chance to listen to people's experiences, to value their stories, and to understand that our stories and our efforts grow out of making meaningful connections with one another. Our hope is that their words motivate you, the reader, to think about your story and how it might connect to our efforts outlined here-to build a diverse and inclusive community of mathematical practice. Both authors invite you to share with us your story, your questions, or your interest in participating

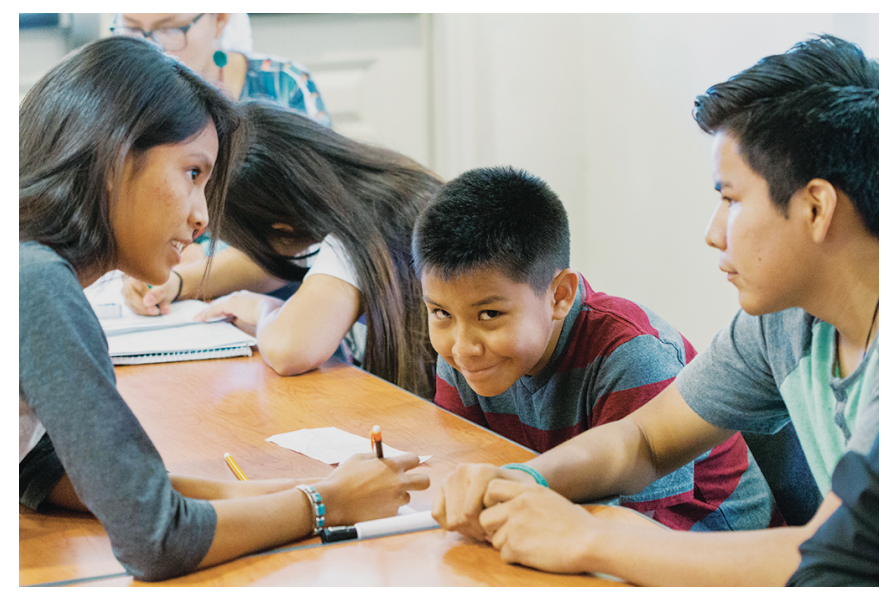

Collaboration is key at Summer Math Camp.

Participants huddle to debate a solution. by using the contact information included in the footnotes about the authors.

\section{PERSPECTIVES}

Henry Austin (Junior Mentor. High School Student, Allendale, MI):

I found it quite remarkable to watch students' eyes light up when they arrived at a solution as it was clear that they were truly interested and engaged in what they were learning. I have taken math for my entire school career...but the math that the students at AIMC learn is much different than a traditional classroom. Students are able to use math as a reasoning tool and understand its application in the natural world, rather than simply arriving at an answer. Upon completion of the camp, I found myself asking, "Why isn't this math taught in school?"

Ann Cherrier (Champion. Middle School Math Teacher, Anchorage, AK):

I witnessed a group of young people from different communities [bound] together by their heritage and culture and mathematics blossom from scarcely speaking a single word to one another to problem-solving, sharing their thinking, trying new strategies, critiquing each other's solutions, and getting excited about getting that much closer to a solution. Best of all was seeing all this occur with smiles, synergistic energy, and excitement about mathematics.

What I experienced has motivated me to begin a similar program here in Anchorage, Alaska. Starting on a smaller scale, I am planning to establish an indigenous math circle after-school program at two Title I middle schools in the Anchorage School District. Mathematical literacy is a powerful weapon in the fight against poverty and in promoting healthy families and good paying jobs.

Craig Young (Regional Coordinator. Middle School Math Teacher, Tuba City, AZ):

Currently, I am the Regional Coordinator for AIMC West, covering the Western Navajo Nation, roughly half the size of the state of West Virginia. I have been involved with the Navajo Math Circles Project as a college student and later as an educator. I run a Math Circle Program at Tuba City Boarding School in Tuba City, Arizona. Our Navajo youth needed a program that empowered them in a traditional holistic approach that complimented their way of life and way of thinking. All indigenous communities have a history of complex mathematics and 
sciences through their cultures, and the Math Circles help our indigenous youth. Our students rediscover themselves and are confident after going through our program.

LaVerne Lomakema (Regional Coordinator. High School Math Teacher, Keams Canyon, AZ):

As a Native teacher on a Native American reservation, I see the crucial need to stress the importance of the mathematical field in our education system. Most Native communities are already economically disadvantaged, this creates a huge stress on many communities. If students could understand the role of mathematics in their communities and within mainstream society, their opportunities would be endless. The key is to get the kids excited about math and realize the many doors it could open for them in the future. The math circles model is a great opportunity for Native children to look at the field of mathematics in a different context. It gives the students a chance to explore and understand mathematical models. Math circles would be a great opportunity for any Native school.

Donna Fernandez (Regional Coordinator. IB Coordinator, Navajo Preparatory School, Farmington, NM): I coordinate the four Corners Math Teachers' Circle (4CMTC) for the tribal communities. The teachers are in $\mathrm{K}-12$ and primarily serve Native American students. Being a part of the Math Teachers' Circle has given me a renewed sense of the joy of math and built my confidence in problem solving. I get so excited to work with other teachers/professionals talking about the multiple ways to solve a problem. The camps and student circles show me how, when we give students open-problems and allow them to collaborate, they dig deep for patterns and understanding.

AIMC Math Circles values [my students'] intuitive nature of looking at patterns in our world for understanding. It allows students and teachers the opportunity to think about the math and not just computational and memory skills. Native American communities benefit from this model; teachers and students feel empowered by collaborating and struggling. Dr. Henry Fowler tells students at each camp that our Native communities need leaders and the best way to be a leader is to have a strong educational foundation, and math is the base of the foundation. It makes you feel confident to be that leader.
Natanii Yazzie (Participant. High School Student, Gallup, NM):

I have been a participant of the AIMC and NNMC for four years and recently I've been a team captain for three years representing my group and providing feedback for the math camp competition presentations. Through the years of attending the math circles, I've developed a passion for mathematics that truly changed my academic path and ignited an ambition I never knew I had inside of me. I've gained many valuable friendships and connections with professors across the nation with whom I could learn from to better prepare for college. It has been an absolutely eye opening and life changing experience for me, and I wish for other Native groups to attend this amazing program. I found the program to be effective at growing critical thinking skills essential for success in college, and for thriving in both modern and traditional Native worlds.

David Austin (Facilitator and Keynote Speaker. Professor, Grand Valley State University, MI):

For many members of underrepresented groups, education can appear to be a path leading away from one's family and culture and into some new and strange place. Particularly for indigenous students in the American southwest, who frequently deal with poverty, geographic isolation, and limited educational opportunities, education and the opportunities that come with it can often separate families physically or by experience and values.

The past two summers, I have had the pleasure of participating in summer math camps for indigenous $6-12$ th graders. The camps are structured to support students in their own culture. First, a group of mathematicians travels to their land, and, while some students may travel many hours to reach the camp, they share a common background with their fellow campers. Families, particularly parents, are welcomed into the camp as well and participate in the opening and closing ceremonies. Traditional meals served by tribal elders are sometimes on the menu. Every day includes cultural activities, led by Native mentors, that are both fun and authentic. All of this conveys a message to the campers and their families that they belong and are safe.

The mathematical content of these camps is similarly rich. In a typical day, students collaboratively explore problems that require little mathematical prerequisite knowledge; all 
students, from grades 6 through 12, are able to work on the same problems. At the same time, these problems are often open-ended and naturally lend themselves to further exploration in considerable depth. At the end of the camp, students participate in a "math wrangle," a friendly competition in which teams of students present their work to the entire group and are assessed on the quality of their presentation.

What's more, the AIMC hosts workshops for teachers in schools with a large Native population and provides support to teachers leading math circles for students in their schools. In short, the goal of the AIMC is to embed meaningful mathematics within indigenous culture and provide support so that it can flourish on its own.

As a member of the Choctaw nation who grew up in Oklahoma, my experiences don't perfectly overlap with those of the campers, but I do know the challenge of working to become a professional mathematician while feeling like "home" is far away. This is something that I'm able to share with the students, and I hope they hear in my story a message that it is possible to learn to live in two worlds at the same time, that there is great meaning to be found in accepting that challenge, and that there are resources to help.

On the final day of the camp, I gave a presentation to students and their families about sunflower seeds and continued fractions. What was particularly pleasing to me was that parents responded to questions that I asked as frequently as students and often with a look of surprise that they were able to contribute. I hope that this gave parents and families an understanding of what the students experienced at the camp and a taste of where they may be headed. While there are more opportunities to expand this work into other indigenous communities, these ideas may be useful as mathematicians reach out to welcome other groups into our discipline.

Perspectives such as these motivate our work and remind us of how much we, the authors and directors of AIMC, are learning as we engage in this effort. One important conclusion we have come to after working with indigenous youths for a number of years is that, while it is easy to look at the statistics on poverty, academic success, STEM participation, and the like, and to construct a model that casts "indigenous" as a deficit, this superficial approach fails to recognize the inherent assets or affordances that indigenous students bring to mathematical problem solving and post-secondary participation in STEM fields. Many of these students are bilingual, speaking their indigenous languages at home and English outside of the home. Bilingual children have been shown to acquire third and fourth languages with easier facility than monolinguals. In our experience, the flexibility of mind required to approach new grammars and vocabularies constitutes a true asset in terms of learning mathematics. Moreover, many indigenous languages reflect embedded philosophies that are radically different from the Western philosophies embedded in English. Being fluent in English and an indigenous language therefore magnifies that flexibility of mind, fostering the kind of creativity that leads to great mathematical discoveries.

Indigenous peoples are bicultural (and often multicultural) by geography and history, navigating every day the norms, traditions, and world views of those cultures. We posit that with two cultures, they have not just average abilities, but extraordinary gifts for learning third and fourth cultures. Mathematics is just such a culture that they can absorb nimbly. The Alliance of Indigenous Math Circles is an effort to bring together many beautiful cultures, knowing that a culture of mathematics, as Craig Young says in his perspective above, always has been part of indigenous culture, and that as cultures mix, they change.

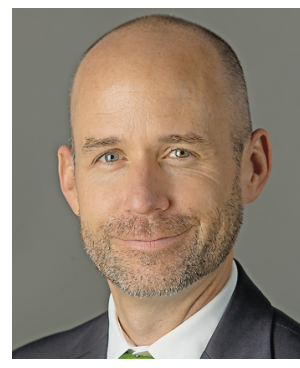

Bob Klein

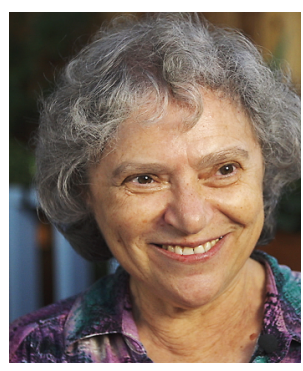

Tatiana Shubin

\section{Credits}

Article photos are by Bob Klein.

Photo of Bob Klein is by Ben Siegel.

Photo of Tatiana Shubin is by George Csicsery. 